[4] Örem A, Ertürk M, Cimşit G, Kural BV. Effect of plasma from patients with Behçet disease on the production of nitricoxide in cultured human umbilical vein endothelial cells. Med Princ Pract 2004;13:35-8.

Disclosure of Interests: None declared

DOI: 10.1136/annrheumdis-2020-eular.5423

\section{AB1013 CYCLOPHOSPHAMIDE VS AZATHIOPRINE FOR THE TREATMENT OF CONNECTIVE TISSUE RELATED INTERSTITIAL LUNG DISEASE}

H. Satış ${ }^{1}$, M. Onut ${ }^{1}$, R. Bilici Salman ${ }^{1}, \underline{\text { H. Babaoglu }}{ }^{1}$, N. Atas ${ }^{1}$, A. Avanoğlu Güler ${ }^{1}$, H. Karadeniz ${ }^{1}$, D. Yapar ${ }^{1}$, N. Kayahan², H. Küçük3, S. Haznedaroglu' ${ }^{1}$, B. Goker ${ }^{1}$, M. A. Ozturk' ${ }^{1}$ A. Tufan ${ }^{1}$, H. Türktaş ${ }^{1} .{ }^{1}$ Gazi University Faculty of Medicine Hospital, Ankara, Turkey; ${ }^{2}$ Gülhane Research and Training Hospital, Ankara, Turkey; 3Yenimahalle Research and Training Hospital, Ankara, Turkey

Background: Interstitial lung disease (ILD) is a common morbidity and mortalitiy reason for connective tissue disorders (CTD). Data related to treatment options in the literature is limited

Objectives: To describe the role of azathiopurine (AZA) in the first line treatment of connective tissue disease related interstitial lung disease CTD-ILD, comparing with cyclophosphamide (CYC)

Methods: Between 2009 and 2019 all interstitial lung disease patients admitting rheumatology or pulmonology department were retrospectively evaluated. Among those patients, as an first line regimen treated with either azathiopurine or cyclophospamide were included. Primary end point was FVC percentage change at 6 th month.

Results: Among 328 CTD-ILD, 57 patients had AZA treat and 79 patients had CYC for the first line treatment. Patients treated with AZA tend to have limited disease and older age. CYC treatment had a mean of $2,41 \%$ increase in FVC but in AZA -1,44\% decrease in FVC predicted ( $p: 0,041) 5$ major CTD groups were defined (systemic sclerosis (SSc), rheumatoid arthritis (RA), primer sjögren syndrome ( $\mathrm{SSS}$ ), dermatomyositis/ polimyositis (PM/DM), autoimmune features of intestitial lung disease (IPAF)). AZA had similar efficacy in, PM/DM and IPAF groups but worse outcome in SSc, RA and pSS compared to CYC

Conclusion: AZA treatment might be an option patients with limited disease extent and the diagnosis of PM/DM or IPAF. CYC was a better treatment in SSC, RA and pSS patients

References:

[1] Kocheril, S.V., et al., Comparison of disease progression and mortality of connective tissue disease-related interstitial lung disease and idiopathic interstitial pneumonia. Arthritis Care \& Research: Official Journal of the American College of Rheumatology, 2005. 53(4): p. 549-557.

Table 1. CYC: treatment responses of cyclophosphamide and azathiopurine regimens AZA: azathiopurine CYC: cyclophosphamide, AZA: azathiopurine CTD: connective tissue disease, SSc:Systemic Sclerosis, RA: Rheumatoid Arthritis, pSS: primary sjogren syndrome, DM/PM/ ASS: Dermatomyositis / Polimyositis/Antisynthetase Syndrome, IPAF: Idiopahtic interstital fibrosis with autoimmune feautres, FVC: forced vital capacity

\begin{tabular}{lccc}
\hline & AZA(n:43) & CYC $(\mathrm{n}: 72)$ & $p$ \\
\hline Progression(overall) & $39,3 \%$ & $15,3 \%$ & 0,013 \\
SSc (n:47) & $60 \%$ & $11,9 \%$ & 0,029 \\
RA(n:16) & $62,5 \%$ & $25 \%$ & $>0,05$ \\
pSS(n:16) & $71,4 \%$ & $11,1 \%$ & 0,035 \\
DM/PM/ASS(n:14) & $11,1 \%$ & - & $>0,05$ \\
IPAF(n:20) & $28,6 \%$ & $23,1 \%$ & $>0,05$ \\
FVC change (overall) (It) & $-, 129 \pm 0,741$ & $0,024 \pm 0,249$ & 0,189 \\
SSc (n:47) & $-0,086 \pm 181$ & $0,025 \pm 0,351$ & 0,286 \\
RA(n:16) & $-0,553 \pm 1,521$ & $-022 \pm 0,262$ & 0,341 \\
pSS(n:16) & $-0,328 \pm 0,242$ & $0,014 \pm 0,313$ & 0,167 \\
DM/PM/ASS(n:14) & $-0,0089 \pm 0,370$ & $0,120 \pm 0,037$ & 0,316 \\
IPAF(n:20) & $0,123 \pm 0,320$ & $0,120 \pm 0,101$ & 0,981 \\
FVC change (overall) (\%) & $-1,44 \pm 10,65$ & $2,41 \pm 7,55$ & 0,041 \\
SSc (n:47) & $-3,00 \pm 3,67$ & $2,23 \pm 8,27$ & 0,031 \\
RA(n:16) & $-3,50 \pm 9,65$ & $-1,75 \pm 4,65$ & 0,654 \\
pSS(n:16) & $-6,71 \pm 15,97$ & $3,33 \pm 8,35$ & 0,027 \\
DM/PM/ASS(n:14) & $0,00 \pm 11,85$ & $4,40 \pm 2,70$ & 0,313 \\
IPAF(n:20) & $2,06 \pm 9,04$ & $5,28 \pm 6,70$ & 0,380 \\
\hline
\end{tabular}

Disclosure of Interests: None declared

DOI: 10.1136/annrheumdis-2020-eular.3642

\section{AB1014 \\ CLINICAL AND LABORATORY PHENOTYPES IN PATIENTS DIAGNOSED WITH SARCOIDOSIS IN A VETERAN'S HOSPITAL}

J. M. Bello-Gualtero ${ }^{1}$, M. Carreno-Jaimes ${ }^{1}$, R. Reyes ${ }^{1}$, P. Medina ${ }^{1}$, M. C. Romero ${ }^{1}$, D. Padilla-Ortiz ${ }^{1}$, Y. M. Chamorro-Melo ${ }^{1}$, D. Rincón-Riaño ${ }^{1}$ on behalf of Not Apply. ${ }^{1}$ Central Military Hospital, Bogotá, Colombia

Background: Sarcoidosis is a disease which affect any organ or tissue in the body, but is predisposed to lung involvement in up to $90 \%$ of cases. Its cause is not yet established, although a multicausal model with genetic, environmental and infectious factors is proposed.

Objectives: Determine the clinical, paraclinical characteristics and survival of patients diagnosed with Sarcoidosis treated at the Central Military Hospital.

Methods: Historical cohort study of patients who were diagnosed with Sarcoidosis at the Central Military Hospital in the last 5 years. A review of medical records, laboratory results and radiological studies was performed and verification of survival status free of mortality was documented by independent outcomes group. A descriptive analysis was done using standard methods and non-parametric survival was calculated using the Kaplan Meyer method with confidence interva in STATA 15.

Results: Twenty patients with confirmatory biopsy of sarcoidosis. Average age $44 \pm 15.3$ years, $55 \%(11 / 20)$ of the patients were men. Dyspnea was the most frequent reason for consultation $50 \%(10 / 20)$, S. Löfgren $10 \%(2 / 20)$, the lung was the most frequent location $65 \%(13 / 20)$, mild hypercalcemia and norma enzyme converting angiotensin levels were found. $60 \%$ of patients had grade 1 commitment on the chest radiograph. $60 \%(12 / 20)$ of the patients received immunosuppressive treatment. The overall survival at 5 years was $92 \%$ (95\% Cl 57-99)

Conclusion: Sarcoidosis is a disease of young patients with a slight predominance in men. Pulmonary involvement is the most frequent, followed by medias tinal nodal involvement. Most patients received steroid treatment at some time in their life. The long-term survival of the disease is more than $90 \%$, which indicates its benign course.

References:

[1] Iannuzzi MC, Rybicki BA, Teirstein AS. Sarcoidosis.N Engl J Med. 2007 Nov 22;357(21):2153-65.

[2] Arkema EV, Grunewald J, Kullberg S, Eklund A, Askling J. Sarcoidosis incidence and prevalence: a nationwide register-based assessment in Sweden. Eur Respir J 2016; 48: 1690-1699.

Acknowledgments: Not aply

Disclosure of Interests: None declared

DOI: 10.1136/annrheumdis-2020-eular.5672

\section{AB1015}

FEATURES OF CLINICAL AND LABORATORY ACTIVITY IN IDIOPATHIC LOBULAR PANNICULITIS.

B. Belov ${ }^{1}$, O. Egorova ${ }^{1}$, S. Glukhova ${ }^{1}$. V.A. Nasonova Research Institute of Rheumatology, Moscow, Russian Federation

Background: The pathological process of idiopathic lobular panniculitis (ILP) comes from disorganization of the adipose tissue which leads to its fibrosis and atrophy. It is assumed that the disease is of immunopathological nature, as evidenced by disorders of lipid peroxidation, high $\mathrm{CIC}$, excess production of leptin (LEP), IL-2 and TNF. The latter is considered a key cytokine involved in the development of the disease.

Objectives: to establish the relationship between the clinical picture and immuno-inflammatory parameters (CRP, LEP and TNF) in patients with ILP.

Methods: We examined 67 patients ( 9 men, 58 women) with the ILP diagnosis verified in the Institute in 2007-2017. The age of patients ranged from 20 to 76 , the average duration of the disease was 78.91[48.50] months. In addition to general clinical examination we performed immunological, histological studies, computed tomography of the chest, tuberculin samples. To determine the body mass index of patients, the values of the Quetelet index (QI) were used.

Results: The disease was found in all age groups, but more than half of the patients $(57 \%)$ were in the most active working age of $45-60$. ILP started with painful induration of various localization, except for the face, and increased temperature reaction of the body. The mean value of QI $24.10 \pm 12.01 \mathrm{~cm} / \mathrm{kg}$ corresponded to normal body weight $(p=0.180)$. 41 patients $(61.19 \%)$ demonstrated normal QI and preobesity at the age before 45 in $30.3 \%$ of cases $(p=0.36)$. Obesity of degree II and III was recorded for 7 patients (10.44\%). QI correlated with the age of patients $(r=0.43, p<0.05)$. ESR correlated with VAS pain intensity $(r=0.29, p<0.05)$, lesion area $(r=0.50, p<0.05)$, temperature increase $(r=0.68$, $p<0.05$, ) and CRP level $(r=0.68, p<0.05)$. The concentration of CRP correlated with VAS pain intensity $(r=0.46, p<0.05)$, lesion area $(r=0.57, p<0.05)$, stage I node $(r=0.41, p<0.05)$ and TNF- $a$ concentration $(r=0.32, p<0.05)$. The increase 
of the last indicator had a direct correlation with stage II of the node ( $r=0.41$, $p<0.05$, ) and with the level of LEP $(r=0.28, p<0.05)$, and an inverse correlation with the number of nodes $(r=-0.24, p<0.05)$. The level of LEP increased in 35 patients $(52.23 \%)$, had a direct correlation with QI $(r=0.46, p<0.05)$, the affected area $(r=0.31, p<0.05)$, the concentration of CRP $(r=0.36, p<0.05)$ and an inverse correlation with the number of nodes $(r=-0.33, p<0.05)$.

Conclusion: it is obvious that in case of ILP there is a need to increase knowledge about the markers of inflammatory activity (ESR, CRP, TNF- $a$ and LEP) which correlated with the area of the lesion, VAS pain intensity and temperature increase.

Disclosure of Interests: None declared

DOI: 10.1136/annrheumdis-2020-eular.1046

\section{AB1016 RATE OF PREDEFINING DISEASE ACTIVITY, REMISSION AND RELAPSE OF ADULT-ONSET STILL'S DISEASE: SYSTEMATIC LITERATURE REVIEW}

\section{E. Bilgin ${ }^{1}$, U. Kalyoncu'. ${ }^{1}$ Hacettepe Üniversitesi Tıp Fakültesi, Internal} Medicine, Division of Rheumatology, Ankara, Turkey

Background: Adult-onset Still's disease (AOSD) is a rare, multisystem and auto-inflammatory disorder. Although several scoring systems are proposed to describe AOSD disease activity, there is no agreement on the definition of disease activity, remission or relapse of AOSD.

Objectives: Aim of this literature review was to determine the rates of defining "disease activity", "remission" and "relapse" of AOSD.

Methods: We performed a systematic review (May 2019) on Pubmed by using the MeSh word "Adult-onset Still's disease"; results were restricted to human studies and English language. We excluded case reports, reviews and studies including less than 10 patients; 215 articles were recruited for final assessment. Of this 215 article, we reached the full-texts of the 181 articles. Final assessment was done with 181 articles. In these articles, we searched whether the definitions of disease activity, remission or relaps were made or not.

Results: Total of 181 articles were included to analysis. Mean age was $37.2 \pm 6.6$ and $73.6 \%$ of patients was female. Articles were devided to 4 main groups according to main focus related to AOSD: Observational studies, laboratory studies, genetic studies and clinical trials. Diagnosis of AOSD was according to Yamaguchi criteria in 159 (87.8\%) of articles and Yamaguchi criteria was the most commonly used criteria set. Disease activity was defined in $96(54.1 \%)$ of articles. Remission and relapse were defined in $52(28.7 \%)$ and 18 (10\%) of articles, respectively. Most commonly used definition of disease activity was the "systemic score" which was defined by Pouchet et al. Rates of defining "disease activity", "remission" and "relapse" according to 4 main groups were given in Table 1.

Table 1. Rates of disease activity, remission and relapse reporting based on 4 main article groups

\begin{tabular}{lccccccc}
\hline Article group & $\mathrm{n}(\%)$ & $\begin{array}{c}\text { Disease } \\
\text { activity (n,\%) }\end{array}$ & $\mathrm{p}$ & $\begin{array}{c}\text { Remission } \\
(\mathrm{n}, \%)\end{array}$ & $\mathrm{p}$ & $\begin{array}{c}\text { Relapse } \\
(\mathrm{n}, \%)\end{array}$ & $\mathrm{p}$ \\
\hline Observational & $70(38.7)$ & $18(25.7)$ & $<0.001$ & $17(24.3)$ & $<0.001$ & $8(11.4)<0.001$ \\
$\quad$ Studies & & & & & & & \\
Laboratory Studies & $72(39.8)$ & $46(63.9)$ & & $15(20.8)$ & $2(2.8)$ \\
Genetic Studies & $17(9.4)$ & $5(29.4)$ & & $2(11.8)$ & $0(0)$ \\
$\quad$ Clinical & $22(12.2)$ & $14(63.6)$ & $18(81.8)$ & $8(36.4)$ \\
Trial & & & & &
\end{tabular}

Conclusion: In recent years, new treatment options become available for AOSD. However, data about how to measure the AOSD activity in largely missing. Definitions of disease activity, remission or relapse are missing in the most of the studies, including clinical trials, in current literature. Future studies are needed for this issue.
References: None

Disclosure of Interests: Emre Bilgin: None declared, Umut Kalyoncu Consultant of: Abbvie, Amgen, Janssen, Lilly, Novartis, UCB

DOI: 10.1136/annrheumdis-2020-eular.515

\section{AB1017 1 ANTI RANK LIGAND IN ACUTE CHARCOT NEURO- OSTEOATHROPATHY OF THE FOOT: A PROMISING TREATMENT}

S. Carvès $^{1,2}$, J. Henry ${ }^{1,2}$, M. Bourgeon Ghittori ${ }^{1,2}$, R. Belkhir ${ }^{1,2}$, G. Nocturne ${ }^{1,2}$, F. Besson ${ }^{1,2}$, G. Cluzel ${ }^{1,2}$, M. Creze ${ }^{1,2}$, R. Seror ${ }^{1,2}$, X. Mariette ${ }^{1,2}$. ${ }^{1}$ Hôpitaux Universitaires Paris-Sud, Le Kremlin-Bicêtre, France; ${ }^{2}$ Assistance Publique des Hôpitaux de Paris, Paris, France

Background: Acute Charcot neuroarthropathy $(\mathrm{CN})$ of the foot is a rare and severe complication of peripheral neuropathy leading to joint destruction. Usual treatment rely on standard pressure offloading and no pharmacological treatment is available. Inflammation and increased osteoclastic activity via receptor activator of nuclear factor (RANK) ligand are major features of acute CN.

Objectives: To assess clinical, metabolic and radiographic effect of denosumab a fully human monoclonal antibody against RANK ligand, in acute $\mathrm{CN}$.

Methods: In this open study, we included all consecutive patients with acute $\mathrm{CN}$ treated with denosumab $60 \mathrm{mg}$ in our mixed rheumatology/diabetes clinic dedicated to diabetic foot. Diagnosis of acute $\mathrm{CN}$ was based on clinical presentation and supported by biology, radiography, magnetic resonance imaging (MRI). Baseline and follow-up assessment included clinical examination and emission tomography-computed tomography (PET-CT).

Results: Seven patients with acute $\mathrm{CN}$ were treated with denosumab between 2017 and 2019 (age from 43 to 70 years). Five were diabetic. All patients received denosumab, because of failure of standard pressure offloading, with evolving joint destruction of midfoot. CN evolves since a median of 6 months (2 to 20) at denosumab initiation. All patients clinically improved after denosumab injection (table). After a mean follow-up of 16 months, only 1/7 patients had a new flare. In the 4 patients with available follow-up X-ray, structural damage remained stable. In all 3 patients with available PET-CT evolution, the maximum standardized uptake lean value (SUL max) decreased.

Three patients were retreated, with a mean interval of 6 months: One patients because of persistent clinical and biological inflammation (CRP $17 \mathrm{mg} / \mathrm{L}$ ), one because of relapse due to intensive walking, and one due to an associated osteoporosis.

No adverse event and hypocalcemia was observed.

Conclusion: One to three injection of denosumab $60 \mathrm{mg}$ was efficient in preventing flare and further bone destruction in a 16 months medium follow up. These results justify the conduction of a randomized control study to assess the efficacy of denosumab as the first-line pharmacological therapy in acute $\mathrm{CN}$.

\section{References:}

[1] Molines $L$ and al. Charcot's foot: Newest findings on its pathophysiology, diagnosis and treatment. Diabetes Metab. Sept 2010;36(4):251-5.

[2] Mabilleau G, and al. Increased osteoclastic activity in acute Charcot's osteoarthropathy: the role of receptor activator of nuclear factor-kappaB ligand. Diabetologia. juin 2008;51(6):1035-40.

Disclosure of Interests: None declared

Disclosure of Interests: Sandrine Carvès: None declared, Julien Henry: None declared, Murielle BOURGEON GHITTORI: None declared, Rakiba Belkhir: None declared, Gaetane Nocturne: None declared, Florent Besson: None declared, Guillaume Cluzel: None declared, Maud Creze: None declared, Raphaèle Seror Consultant of: BMS UCB Pfizer Roche, Xavier Mariette Consultant of: BMS, Gilead, Medimmune, Novartis, Pfizer, Servier, UCB DOI: 10.1136/annrheumdis-2020-eular.4913

Table 1. Baseline characteristics and follow up treatment

\begin{tabular}{|c|c|c|c|c|c|c|c|}
\hline $\mathrm{N}^{\circ}$ patient & 1 & 2 & 3 & 4 & 5 & 6 & 7 \\
\hline Age (years) & 70 & 43 & 64 & 69 & 54 & 57 & 54 \\
\hline Sex & $M$ & $\mathrm{~F}$ & $M$ & $\mathrm{~F}$ & $M$ & $\mathrm{M}$ & $\mathrm{M}$ \\
\hline BMI (kg/m2) & 31.8 & 29.7 & 23.4 & 19 & 40.4 & 39 & 30 \\
\hline Cause of neuropathy & Undetermined & MODY & Type 1 Diabetes & Amyloidosis & Type 2 Diabetes & Type 2 Diabetes & Type 2 Diabetes \\
\hline PET-CT (SUL max) before treatment & $R=7.1 . L=4.9$ & 3.5 & 3.9 & $R=2.9 . L=3.1$ & $\mathrm{R}=\mathrm{L}=3.7$ & 3.1 & 6.6 \\
\hline Number of injections & 1 & 2 & 3 & 3 & 1 & 1 & 1 \\
\hline Number of new flare & 0 & 0 & 2 & 0 & 0 & 0 & 0 \\
\hline Follow up after denosumab (months) & 34 & 22 & 19 & 21 & 10 & $4^{*}$ & $3^{* *}$ \\
\hline Radiography & stable & stable & stable & ND & stable & ND & ND \\
\hline PET-CT (SUL max) after treatmen & $R=4,3 . L=3$. & $\mathrm{R}=\mathrm{L}=0$ & ND & ND & $\mathrm{R}=\mathrm{L}=2.5$ & ND & ND \\
\hline
\end{tabular}

L, left; $R$, right. MODY, Maturity-Onset Diabetes of the Young;

${ }^{*}$ Assessment is scheduled on february 2020 ( ${ }^{* \star}$ march 2020) 